\title{
Power Transformer Mechanical Condition Assessment with a Vibration-based Diagnostic Method
}

\author{
Sergejs Zizins-Malisevs (Latvenergo), Gints Poiss (Doctoral student, Riga Technical University)
}

\begin{abstract}
Vibrations are caused by electrodynamic forces and the effect of a fault can be detected by measuring the vibration level. Vibration-based diagnostic method which is used in Latvenergo and measured vibration results as case studies are presented in this paper.
\end{abstract}

Keywords - Power transformers, vibration measurements, condition assessment.

\section{INTRODUCTION}

Power transformers are one of the most critical and important components both in power plants and in transmission system. Unexpected failures can cause shut-down of a power plant or even an extensive transmission system failure.

Currently various power transformer condition assessment methods are known - insulating oil analysis, dissolved gas analysis (DGA), electrical measurements, infrared thermography, vibration measurements, etc.

Vibration-based diagnostics is one of the most informative methods to detect a mechanical failure.

Vibrations in a transformer occur in its winding and the core. Vibrations in the winding are caused by electrodynamic force when the fault current in the winding interacts with leakage flux. This electro dynamic force is proportional to square current that flows in the winding

Fault current produces axial forces (vertical impact) and radial forces that compress the internal winding or expand the external winding. Such mechanical impact increases the vibration of the core and windings.

The objective of the paper is to present a vibration-based mechanical condition assessment method. Results of the field vibration measurements and case studies are also included in this paper.

\section{DESCRIPTION OF VIBRATION MEASUREMENTS}

Over a period of 7 years, vibration measurements were performed in various measurement points on 5 different power transformers.

In the time period 2009-2014, measurements were performed with the vibration analyzer KOSAR and the vibration sensor VK-310A, and data were processed with software "VESTA 3.0". Whereas in 2015 measurements were performed with the analyzer MICROLOG CMXA70, and sensor CMSS2200, and data were processed with a software manufactured by SKF "Analyst".
All measurements were performed by engineers from the same department and following the same methodology. The obtained results are analyzed in the following case studies.

\section{A. Case study No.1}

In Riga thermal power plant No. 2, vibration measurements were performed on two unit transformers with voltage 110 and $330 \mathrm{kV}$ in the period from 2009 to 2014, as well as on two auxiliary transformers with voltage 15.75 and $17 \mathrm{kV}$ in the period 2012 to 2014. For all transformers 12 measurement points both on the high-voltage (HV) and low-voltage (LV) side were used. Measurement points covered the upper and the lower part of the windings for each transformer phase. Measurements on transformers were performed in two operating modes: no-load and load mode (Table I).

The maximum values of vibration acceleration, velocity and displacement in both modes did not exceed the limits specified according to [1], [2], [3], which indicates the lack of defects.

\section{B. Case study No.2}

In 2015, the same measurements were performed on the transformer TD-333000/330 on 84 measurement points, TD$180000 / 110$ on 54 measurement points, TDT 20000/17 and TDN-20000/15, 75 on 24 measurement points along the whole perimeter, including side surfaces (Table I), [1], which have not been measured previously. The horizontal interval between measurement points was approximately 1 meter. Measurements on vertical surfaces of transformers with voltage rate 110 and $330 \mathrm{kV}$ were performed on three levels, and on transformers with voltage rate 17 and $15.75 \mathrm{kV}-$ on two levels. In addition, 12 vibration sensors were deployed on several measurement points on the high-voltage and lowvoltage side of a transformer, where vibrations were measured also in previous years.

\section{Case study No.3}

In 2009-2013, the measurements on a five-legged unit transformer in the Hydropower Plant "Plavinas" were performed on two levels and on 16 measurement points, where as in 2013 additional vibration measurements were performed on four levels and on 124 measurement points, deployed within less than 1-meter from each other. Sensors were placed on different measurement points compared to those 16 points used for measurements in 2009-2013. Therefore, it allowed comparison only of the maximum vibration parameters (Table I). 
TABLE I

BASIC CHARACTERISTICS OF MAXIMUM VIBRATION PARAMETERS IN NO-LOAD AND LOAD MODE, ACCORDING TO MEASURMENTS PERFORMED BETWEEN 2008 AND 2015

\begin{tabular}{|c|c|c|c|c|c|c|c|}
\hline \multirow{2}{*}{ Device } & \multirow{2}{*}{$\begin{array}{l}\text { Measuring } \\
\text { points }\end{array}$} & \multicolumn{6}{|c|}{ Maximum vibration parameters } \\
\hline & & $\begin{array}{c}\text { Vibration } \\
\text { acceleration } \\
\mathrm{mm} / \mathrm{s}^{2}\end{array}$ & $\begin{array}{l}\text { Velocity } \\
\mathrm{mm} / \mathrm{s}\end{array}$ & $\begin{array}{l}\text { Displacement } \\
\mathrm{mm}\end{array}$ & $\begin{array}{c}\text { Vibration } \\
\text { acceleration } \\
\mathrm{mm} / \mathrm{s}^{2}\end{array}$ & $\begin{array}{l}\text { Velocity, } \\
\mathrm{mm} / \mathrm{s}\end{array}$ & $\begin{array}{l}\text { Displacement } \\
\mathrm{mm}\end{array}$ \\
\hline \multirow{2}{*}{$\begin{array}{c}\text { TD-333000/330 } \\
\text { In operation since } 2008\end{array}$} & $12^{1}$ & 3.31 & 2.78 & 10.62 & 8.57 & 9.55 & 42.89 \\
\hline & $84^{3}$ & 9.00 & 6.50 & 29.20 & 8.10 & 5.50 & 24.30 \\
\hline \multirow{3}{*}{$\begin{array}{c}\text { TD- } 180000 / 110 \\
\text { In operation since } 2008\end{array}$} & $12^{1}$ & 2.80 & 2.61 & 8.98 & 2.86 & 4.30 & 9.53 \\
\hline & $12^{2}$ & 2.40 & 1.60 & 6.60 & 1.60 & 2.40 & 10.80 \\
\hline & $54^{3}$ & 2.70 & 2.60 & 11.70 & 2.40 & 2.70 & 12.10 \\
\hline \multirow{3}{*}{$\begin{array}{c}\text { TDN-20000/15.75 } \\
\text { In operation since } 2008\end{array}$} & $12^{1}$ & 1.37 & 1.43 & 6.42 & 1.39 & 1.51 & 6.80 \\
\hline & $12^{2}$ & 1.30 & 0.90 & 6.20 & 1.3 & 1.00 & 5.70 \\
\hline & $24^{3}$ & 1.30 & 1.50 & 6.20 & 2.0 & 2.10 & 9.20 \\
\hline \multirow{3}{*}{$\begin{array}{c}\text { TC-215000/330 } \\
\text { In operation since } 1994\end{array}$} & $16^{4}$ & 19.70 & 31.03 & 139.46 & 16.88 & 24.89 & 111.45 \\
\hline & $16^{5}$ & 29.13 & 32.24 & 124.90 & 12.05 & 14.85 & 62.38 \\
\hline & $124^{3}$ & 53.19 & 59.77 & 269.07 & 47.20 & 53.12 & 239.16 \\
\hline
\end{tabular}

1. Measured in $2009-2014$.

2 - Measured in 2015. The same measuring points in as in $2009-2014$.

3 - Measured in 2015.

${ }^{4}$ - Measured in 2008 - 2012.

5 - Measured in 2013.

\section{ASSESSING THE CONDITION OF A TRANSFORMER}

The systems used for assessing the vibrations of transformer windings [1], [2], [3], [4] provide results in two categories - in terms of existence or non-existence of defects.

On basis of the measurements performed from 2008 to 2014 on 29 transformers installed in five power plants of the company "Latvenergo" JSC, as well as according to information [1] [3], [4] [10], [11] provided by a similar system as the one used for diagnosing the condition of rotating parts [5], criteria have been developed to characterize the condition of transformers in the following categories: excellent, good, satisfactory and poor.

In order to detect values of vibration parameters, the peak values are measured both in no-load and load mode ranging from 0 to $90 \%$ of nominal rate. Oil temperature is measured in the range from $2{ }^{\circ} \mathrm{C}$ to $55{ }^{\circ} \mathrm{C}$. Until 2011 , the load and temperature values at the side surfaces of a transformer were not recorded.

Each category for condition assessment is characterized below:

Zone A, excellent condition, parameters measured in this zone comply with those of new transformers, just put into service.
Zone B, good condition, transformers have no operational restrictions.

Zone C, satisfactory condition; additional measurements are required in order to specify the technical condition and the impact of defects; in general, transformers will remain in operation until repairs are possible.

Zone $\mathrm{D}$, poor condition, possible damage to the transformer.

The parameters characterizing restrictions to the condition of transformers are explained in Table II.

TABLE II

NUMERICAL VALUES OF VIBRATION PARAMETERS

\begin{tabular}{|c|c|c|c|}
\hline \multirow{2}{*}{ Zones } & \multicolumn{3}{|c|}{ Numerical values of vibration } \\
\cline { 2 - 4 } & $\begin{array}{c}\text { Vibration } \\
\text { acceleration } \\
\mathrm{mm} / \mathrm{s}^{2}\end{array}$ & $\begin{array}{c}\text { Velocity } \\
\mathrm{mm} / \mathrm{s}\end{array}$ & $\begin{array}{c}\text { Displacement } \\
\mathrm{mm}\end{array}$ \\
\hline $\mathrm{A} / \mathrm{B}$ & 4 & 8 & 40 \\
\hline $\mathrm{B} / \mathrm{C}$ & 10 & 20 & 100 \\
\hline $\mathrm{C} / \mathrm{D}$ & 25 & 35 & 150 \\
\hline
\end{tabular}

The condition of transformer's winding and the core was assessed on basis of the worst values of these three vibration characteristics: vibration acceleration, velocity and 
displacement. It allows assessing the dynamic interaction between forces, vibration power and clamping forces. If any vibration values exceeded the upper limit applicable to Zone A, the vibration acceleration was analyzed. Contrary to [3], [4], where existence of vibration acceleration at any frequencies from 0 to $700 \mathrm{~Hz}$ is considered as an indicator of defects, here vibration acceleration values of $4.0 \mathrm{~m} / \mathrm{s}^{2}$ or more on any of these frequencies indicate on potential defects in the frequency range 196-714 Hz. The frequency range of 196$714 \mathrm{~Hz}$ was selected in accordance with requirements [6], [7], [8] for power supply to the Baltic States and Nordic States, Central and Western Europe at a frequency range of $49-51 \mathrm{~Hz}$ for an indefinite period of time. As a rule, at the initial stage of defect development, the total vibration value was caused by looser winding and core, and in $80-90 \%$ cases it was influenced by vibration values at $100 \mathrm{~Hz}$ frequency which complies with statements in [2].

\section{DIAGNOSTIC RESULTS}

If values of measurements performed on the transformer TD-333000/330 are plotted on a graph (Fig. 2.) to depict vibration acceleration acting on the transformer walls on each level, it creates a curve showing the distribution of forces acting on the walls. In 2015. measurements were performed at $41 \%$ nominal load (137.4 MVA), oil temperature $+27{ }^{\circ} \mathrm{C}$ and winding temperature $+29^{\circ} \mathrm{C}$. The layout of sensors is shown in Figure 1.
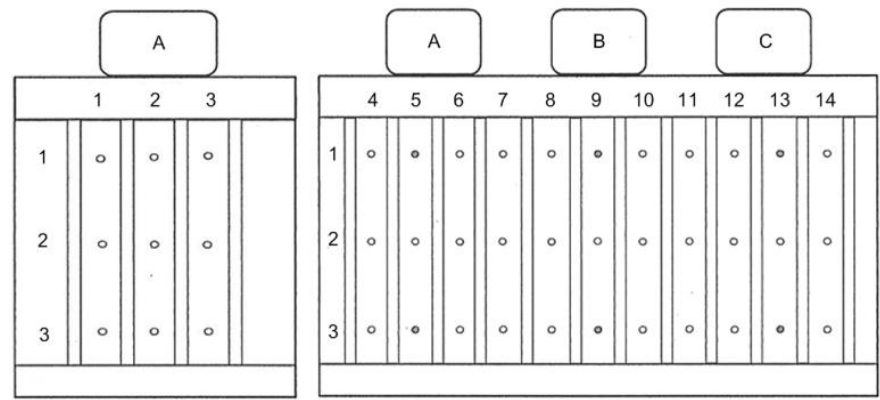

Fig.1. Phase "A" and high voltage side of TD-333000/330 power transformer (measuring points 1-14 and measuring levels 1-3).

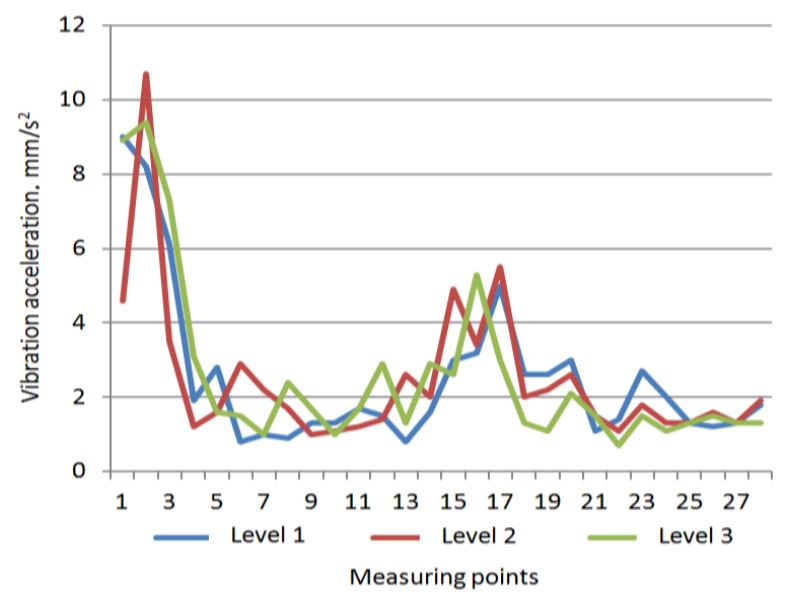

Fig.2. Distribution of acceleration on the walls of the transformer TD $333000 / 330$ in the load mode in 2015.
Measuring points 1-3 on horizontal axis represent vibration acceleration on side surfaces, on the side of phase A, points 414 represent the high voltage side, points $15-17$ represent the side of phase $\mathrm{C}$, but 18-28 represent the medium voltage side.

The total amount of forces acting on the wall of a transformer at frequencies from $\mathrm{f}_{1}$ to $\mathrm{f}_{\mathrm{n}}$, can be expressed as a vector sum of forces.

$$
\vec{F}_{\Sigma}=\vec{F}_{1}+\vec{F}_{2}+\vec{F}_{3}+\ldots \vec{F}_{n}
$$

Where $\mathrm{F}_{\Sigma}$ the total force acting on the wall of a transformer at the point where vibration acceleration is measured;

$F_{1}+F_{2}+F_{3}+\ldots F_{n}$ - forces acting on the transformer wall in the point where vibration acceleration is measured at frequency rates $f_{1}+f_{2}+f_{3}+\ldots f_{n}$.

In vibration acceleration measurements, the extent of force acting on the transformer in perpendicular to its surface was determined. Then the total force was be expressed according to Newton's Second Law:

$$
\vec{a}_{\Sigma} m=\vec{a}_{1} m+\vec{a}_{2} m+\vec{a}_{3} m+\ldots a_{n}
$$

Where $\quad \vec{a}_{\Sigma}$ is the total acceleration acting on the wall of a transformer wall in a the measurement point;

$m$ - mass acting on a transformer wall in a measurement point.

$a_{1}+a_{2}+a_{3}+\ldots a_{n}-$ acceleration acting on the transformer wall in a measurement point at frequency rate $f_{1}+f_{2}+f_{3}+\ldots f_{n}$

According to (1) and (2), the detected total value of vibration acceleration characterizes the force acting on the transformer wall in a measurement point. If vibration characteristics are measured in the same points, the dynamic changes in vibration force at measured levels can be established by comparing the area $S_{\text {avi }}$ that reflects the amount of vibration acceleration. If vibration parameters on side surfaces of a transformer are not known, it is assumed that the intervals between measurement points according to the calculated $S_{a v i}$ are similar and equal to 1 . Therefore, the average measured vibration acceleration value can be used to analyze the dynamic changes in the force acting on the walls of a transformer.

Fig. 3 shows average changes in the total amount of vibrations on levels 1 and 3 (parameter $S_{\text {avi }}$ ).

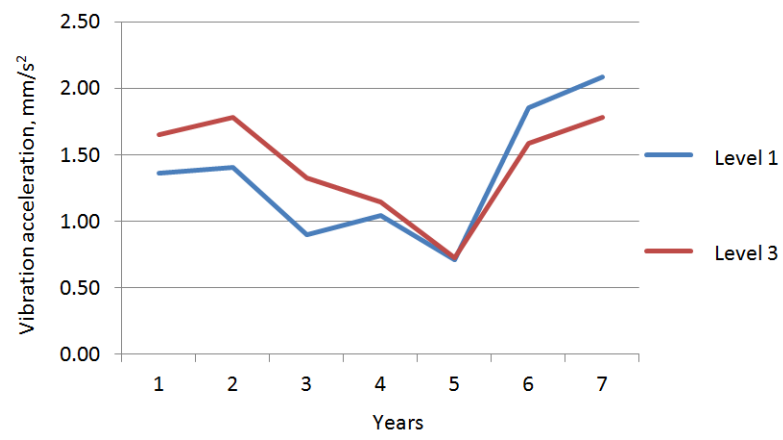

Fig. 3 Changes in the total amount of vibrations on levels 1 and 3 of the transformer TD-333000/330, no-load mode, in 2009-2015 
Between 2009 and 2012, there was a downward trend in vibration force, whereas between 2012 and 2015 an upward trend was observed. The detected vibration values range from 0.361 to $2.8 \mathrm{~m} / \mathrm{s}^{2}$ and do not exceed the upper limit applicable to Zone A; therefore, these values cannot be used for analyzing the dynamic changes in vibration values. However, with regard to the systematic error in measurements performed in 2012 (minimum impact was established on all measurement points), it can be concluded that the amount of forces acting on the walls of a transformer practically have not changed during the period from the first measurements performed in 2009 until 2015. In Riga thermal power plant No. 2, average vibration values of transformers TD-180000/110, TDT 20000/17 and TDT 20000/15 did not exceed the upper limits applicable to Zone A; therefore these values cannot be used for analyzing the dynamic changes in the extent of vibrations.

\section{V.CONCLUCIONS}

The measured vibration values are to some extent influenced by the number and location of vibration sensors deployed on the side surfaces of a transformer. In order to assess the pressure condition of the magnetic core and windings of a transformer and to evaluate maximum vibration values, the interval between sensors should not exceed 1 meter; in all 12 points, sensors should be placed in between the upper and lower limit of windings.

The results of transformer vibrations measured on 12 points, both on the high-voltage (HV) and low-voltage (LV) side, allow assessing the dynamic changes in vibration parameters.

According to the principles for assessing of the condition of rotational parts with an aim to evaluate the overall technical condition of transformers on basis of vibration parameters measured with voltage on, it allowed to:

- characterize the condition of transformers either as excellent - Zone A, good - Zone B, satisfactory - Zone C, or problematic (poor) - Zone $\mathrm{D}$,

- not regard the spectrum of vibration parameters in Zone $\mathrm{A}$, and thus reduce the number of vibration parameters to be assessed,

- optimize the regularity of measurements,

- facilitate the process for diagnosing the condition of a transformer to the operational staff and facilitate decisions on additional diagnostics, repairs and decommissioning.

\section{REFERENCES}

[1] Guidelines for the assessment and life extension of power transformers RD EO 0410-02, 2002 (in Russian).

[2] „Vesta - System for Fast Estimation of the Transformer Winding and Coil Clamping Force". [Online]. Available: http://dimrus.ru/vesta.html

[3] „Operation guide for power transformers”, Energopomiar-elektyka, Gliwice, 2012 (in Polish).

[4] „Technical diagnostics and monitoring of power transformers”, Energopomiar-elektyka, Gliwice, 2012 (in Polish).

[5] ISO 10816-1, „Mechanical vibration - Evaluation of machine vibration by measurements on non-rotating parts - Part 1: General guidelines", 2009.

[6] LVS EN 50150 AC:2011, „Voltage characteristics of electricity supplied by public electricity networks", 2010.
[7] ENSTO-E Network Code for Requirements for Grid Connection Aplicable to all Generators, March 2013

[8] ISO 13373-1, „Condition monitoring and diagnostics of machines Vibration condition monitoring - Part 1: General procedures", 2002.

[9] ISO 10816-3, Mechanical vibration - Evaluation of machine vibration by measurements on non-rotating parts - Part 3: Industrial machines with nominal power above $15 \mathrm{~kW}$ and nominal speeds between $120 \mathrm{r} / \mathrm{min}$ and $15000 \mathrm{r} / \mathrm{min}$ when measured in situ.

[10] Young - Dal Kim, , A study on the Assignment of the Vibration Classes to the Power Transformers in operation $(154 \mathrm{kV})$ “, Journal of the Korean Institute of Illumination and Electrical Installation Engineers Vol. 23, No.11, pp. 52-60, November 2009 .

[11] T Boczar, S Borucki, A.Cichon', M.Lorenc, „The analysis of the lowvoltage transformer core vibration based on vibroacoustic investigations", Česká společnost pro nedestruktivní zkoušení materiálu 37. mezinárodní konference DEFEKTOSKOPIE 2007 Praha, 7.9.11.2007.

Sergej Zizin-Malishev received engineer and M.Sc in electrical engineering from Riga Technical University, Riga, Latvia in 1975 and 2010, respectively. Since 1972 he is employed by Latvian energy company „Latvenergo". Current position - Senior electrical engineer in Technical department of Riga Thermal Power Plant „Latvenergo”. One of the main interests are technical condition control of electrical equipment and adaptation of modern technologies on Thermal Power Plant. Research interests condition prognosis and reliability management of high voltage power transformers.

e-mail: Sergejs.zizins-malisevs@latvenergo.lv 